\title{
Expression of ACE and ACE2 in Patients with Hypertensive Nephrosclerosis
}

\author{
Gang Wang ${ }^{a, c}$ Fernand Mac-Moune Lai ${ }^{b}$ Bonnie C.H. Kwan ${ }^{a}$ Ka-Bik Lai ${ }^{a}$ \\ Kai-Ming Chow ${ }^{a}$ Philip K.T. Li ${ }^{a}$ Cheuk-Chun Szeto $^{a}$ \\ Departments of a Medicine and Therapeutics and ${ }^{\mathrm{b}}$ Anatomical and Cellular Pathology, Prince of Wales Hospital, \\ The Chinese University of Hong Kong, Shatin, Hong Kong, SAR and ' Division of Nephrology, Renmin Hospital of \\ Wuhan University, Wuhan, China
}

\section{Key Words}

Hypertension · ACE2 - Renal disease

\begin{abstract}
Background: The interplay between intrarenal angiotensinconverting enzyme (ACE) and type 2 ACE (ACE2) might play important roles in the pathogenesis of hypertensive nephrosclerosis (HTN), but human data are limited. Methods: Renal biopsy specimens of 41 patients with HTN and 10 transplant donors as controls (CTL) were studied. The glomerular and tubulointerstitial mRNA expression of ACE and ACE2 was measured by laser microdissection and real-time quantitative polymerase chain reaction. The corresponding protein level was determined by immunohistochemistry. Results: Neither the glomerular nor tubulointerstitial mRNA expression of ACE or ACE2 correlated with the corresponding protein level by immunohistochemistry. The tubulointerstitial levels of ACE and ACE2 were significantly lower in HTN than $C T L$, while the glomerular ACE and ACE2 levels were similar between the groups. The tubulointersitial ACE and ACE2 levels significantly correlated with the estimated glomerular filtration rate (GFR) and inversely with the degree of histological damage. The glomerular ACE and ACE2 levels significantly correlated with the rate of GFR decline. The ratio of glomerular ACE and ACE2 level correlated with the estimated GFR and the degree of glomerulosclerosis. Conclusion:
\end{abstract}

Our results suggest that intrarenal ACE and ACE2 may play an important role in the pathogenesis and progression of HTN. Studies based on the mRNA expression of ACE and ACE2 should be cautiously interpreted.

Copyright $\odot 2011$ S. Karger AG, Basel

\section{Introduction}

Hypertensive nephrosclerosis (HTN) is an important complication of systemic hypertension and a major cause of end-stage renal disease (ESRD) [1, 2]. However, the pathogenesis of HTN is not completely clarified. Studies have shown that blocking of the renin-angiotensin system (RAS) with angiotensin-converting enzyme (ACE) inhibitors and angiotensin II receptor blockers (ARBs) ameliorates renal injury and slows the disease progression of HTN, suggesting that RAS activation might play an important role in the pathogenesis of HTN [3-5]. In addition to increased intraglomerular pressure, intrarenal angiotensin II may directly increase the synthesis of growth factors and fibrogenic mediators, which also contribute to the hypertensive renal damage [6-8]. Direct evidence of the pathological relevance of intrarenal RAS in human HTN, however, is limited [9].

To complicate the picture, the newly-discovered type 2 ACE (ACE2) plays a regulatory role in RAS by cleaving

\section{KARGER \\ Fax +4161306 1234 E-Mail karger@karger.ch} www.karger.com

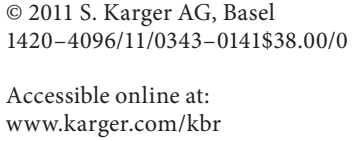

Dr. C.C. Szeto

Department of Medicine and Therapeutics

Prince of Wales Hospital, The Chinese University of Hong Kong

Shatin, NT, Hong Kong, SAR (China)

Tel. +852 2632 3126, E-Mail ccszeto@ cuhk.edu.hk 
angiotensin I to angiotensin 1-9 and angiotensin II to angiotensin 1-7, counterbalancing the detrimental effect of angiotensin II $[10,11]$. It is highly possible that the intrarenal activity of angiotensin II is regulated by the interplay between ACE and ACE2. In the present study, we explore the intrarenal $\mathrm{mRNA}$ expression and protein level of ACE and ACE2 in patients with biopsy-proven HTN.

\section{Subjects and Methods}

\section{Subjects}

We studied 41 consecutive patients in our hospital who had biopsy-proved HTN and no feature of other coexisting renal diseases [12]. Renal biopsy tissue was retrieved for gene expression, immunohistochemistry and morphometric analysis (see below). Clinical data including blood pressure, serum creatinine, urea, electrolyte, albumin, liver enzymes and $24 \mathrm{~h}$ urine protein were reviewed. The glomerular filtration rate (GFR) was estimated by a standard equation [13]. We also studied 10 kidney transplant donors as controls (CTL).

\section{Laser Microdissection}

The method of laser microdissection has been described in our previous study [14]. In essence, immediately after kidney biopsy, part of the tissue was embedded by OCT compound (Sakura, USA) and kept at $-80^{\circ} \mathrm{C}$ under a RNase-free condition for intrarenal gene expression. We then performed laser microdissection to determine the glomerular mRNA expression of ACE and ACE2. Briefly, 8- to $10-\mu \mathrm{m}$ thick cryosections were prepared on a cryostat (Leica Microsystems, Wetzlar, Germany) using disposable microtome blades (Leica Microsystems) under RNase-free conditions. Sections were then mounted on glass slides covered with a polyethylene naphthalate membrane (PALM Microlaser Technologies, Bernried, Germany) and were treated with UV irradiation and RNase Away (Invitrogen, Life Technologies, Pa., USA) prior to use. After being fixed in $70 \%$ ethanol for $2 \mathrm{~min}$, the sections were stained according to the following protocol: DEPC water 1 min, Mayer's hemotoxylin (Sigma, USA) solution $30 \mathrm{~s}$, RNase-free water $1 \mathrm{~min}, 50 \%$ ethanol $1 \mathrm{~min}, 70 \%$ ethanol $1 \mathrm{~min}$, $100 \%$ ethanol 1 min twice, and air-dried $10 \mathrm{~min}$.

Next, PALM Microlaser Systems (PALM, Wolfratshausen, Germany), which is equipped with a pulsed high-quality laser beam, computer-controlled microscope stage and micromanipulator was used to perform microdissection of the prepared slides. Under direct visual control, $20 \pm 5$ glomerular areas of each case were isolated by the focused nitrogen laser beam and then catapulted into different microcentrifuge caps, which were filled with guanidine thiocyanate containing lysis buffer (buffer RLT; Qiagen, Inc., Canada). The tissue lysate of isolated glomerulus was then stored at $-80^{\circ} \mathrm{C}$ until RNA extraction was performed.

\section{Measurement of Intra-Renal Gene Expression}

RNeasy Micro kits were used to extract total RNA from microdissected tissue according to the manufacturer's protocol. DNase was used to wipe off probable genomic DNA. For reverse transcription, $5 \mu$ l total RNA was mixed with $1 \mu$ l random primers (150 ng), $1 \mu \mathrm{ldNTP}$ mix (10 mM each), $4 \mu \mathrm{l} 5 \times$ first-strand buffer, $2 \mu$ l DTT (0.1 M), $1 \mu$ l (200 U) Superscript II RNase H reverse transcriptase (all from Invitrogen, Life Technologies) and made up to $20 \mu \mathrm{l}$ with $\mathrm{H}_{2} \mathrm{O}$. Reverse transcription was performed at $65^{\circ} \mathrm{C}$ for $5 \mathrm{~min}, 25^{\circ} \mathrm{C}$ for $10 \mathrm{~min}, 42^{\circ} \mathrm{C}$ for $50 \mathrm{~min}$, and the inactivated reaction at $70^{\circ} \mathrm{C}$ for $10 \mathrm{~min}$. The resulting cDNA was stored at $-80^{\circ} \mathrm{C}$ until use.

We quantified intrarenal expression of ACE and ACE2 using the ABI Prism 7700 Sequence Detection System (Applied Biosystems, Foster City, Calif., USA). Commercially available TaqMan ${ }^{\circledR}$ primers and probes, including two unlabeled PCR primers and one FAM ${ }^{\mathrm{TM}}$ dye-labeled TaqMan MGB probe were used for all target genes (all from Applied Biosystems). The primer and probe set was deliberately designed across the intron-exon boundary so as not to detect probable genomic DNA. For the real-time quantitative polymerase chain reaction, $10 \mu$ l universal master mix, $1 \mu l$ primer and probe set, $2 \mu \mathrm{lcDNA}$, and $7 \mu \mathrm{H} \mathrm{H}_{2} \mathrm{O}$ were mixed to make a $20-\mu l$ reaction volume. Each sample was run in triplicate. Time quantitative polymerase chain reactions were performed at $50^{\circ} \mathrm{C}$ for $2 \mathrm{~min}, 95^{\circ} \mathrm{C}$ for $10 \mathrm{~min}$, followed by 40 cycles at $95^{\circ} \mathrm{C}$ for $15 \mathrm{~s}$ and $60^{\circ} \mathrm{C}$ for $1 \mathrm{~min}$. $18 \mathrm{~S}$ rRNA (Applied Biosystems) was used as a housekeeping gene to normalize the mRNA expression level of each target gene. Results were analyzed with Sequence Detection Software version 1.7 (Applied Biosystems). In order to calculate the differences of expression level for each target gene among samples, the $\Delta \Delta \mathrm{C}_{\mathrm{T}}$ method for relative quantitation was used according to the manufacturer's manual [15].

\section{Immunohistochemistry and Morphometric Study of Kidney}

Biopsy

The intrarenal ACE and ACE2 expression at protein level was explored by a standard immunohistochemical technique. Briefly, the renal tissue was fixed in $10 \%$ neutral buffered formaldehyde overnight and then dehydrated by alcohol and embedded in paraffin. $4-\mu \mathrm{m}$ thick sections of renal biopsy specimens of each patient were prepared on precoated slides and deparaffinized in xylene and rehydrated by graded alcohol. Antigens were unmasked by heat treatment $\left(95^{\circ} \mathrm{C}\right.$ for $\left.6 \mathrm{~min}\right)$ in $10 \mathrm{mM}$ sodium citrate buffer, pH 6.0. Rabbit ImmunoCruz ${ }^{\mathrm{TM}}$ staining system (Santa Cruz Biotechnology, Inc., Santa Cruz, Calif., USA) was then used for staining. Briefly, endogenous peroxidase activity was quenched by peroxidase block for $5 \mathrm{~min}$ at room temperature. Sections were then incubated in a serum block for $20 \mathrm{~min}$ at room temperature. Rabbit polyclonal to ACE (catalog No. sc-20791; Santa Cruz Biotechnology, Inc.) and ACE2 (catalog code ab15348; Abcam, Cambridge, UK) were diluted in a serum block at a concentration of 1:500. Specimens were then incubated with dilute primary antibody at $4^{\circ} \mathrm{C}$ overnight, followed by incubation with biotinylated secondary antibody and HRP-streptavidin complex at room temperature for $30 \mathrm{~min}$ each. After incubation with DAB chromogen for $5 \mathrm{~min}$, slides were counterstained with hematoxylin for 2 min. Sections were dehydrated with graded alcohol and xylene, covered with Histomount (VWR, Inc., Poole, UK) and a coverslip.

As described in our previous studies [16, 17], Jones' silver staining was also performed on 5 - $\mu \mathrm{m}$ thick sections of renal biopsy specimens of each patient to assess renal scarring.

We used a computerized image analysis method to quantify the degree of immunohistochemical and silver staining. Briefly, a Leica Twin Pro image analysis system (Leica Microsystems) was connected to a Leica DC500 digital camera on a Leica DMRXA2 microscope working with a $40 \times$ objective (final calibration: 0.258 
Fig. 1. Comparisons of a glomerular and b tubulointerstitial mRNA expression of ACE and ACE2 between patients with

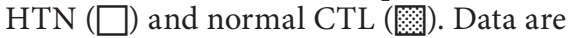
compared by the Mann-Whitney U test.

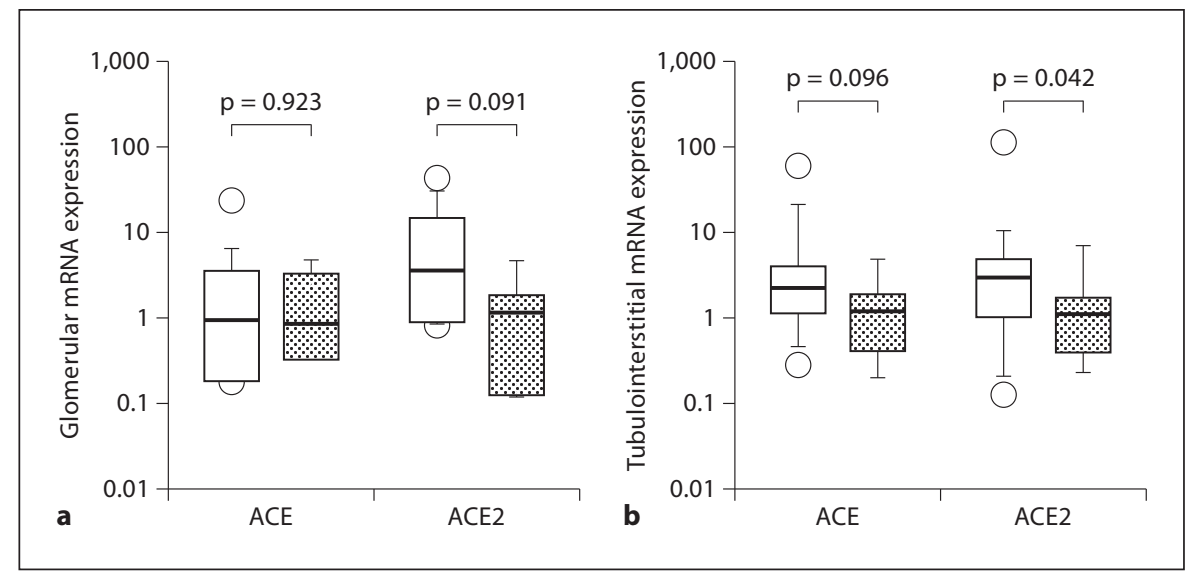

$\mathrm{mm} /$ pixel) and to a microcomputer for storage of the morphometric measurements and to perform image analysis by using imageanalyzing software (MetaMorph 4.0; Universal Imaging Corp., Downingtown, Pa., USA). Ten glomeruli and ten randomly selected tubular interstitial areas were assessed in each patient and the average protein level and scarring degree in glomerular and tubulointerstitial areas, as represented by the percentage of the area with positive staining, were computed for each patient.

\section{Clinical Follow-Up}

All patients were followed for at least 12 months after renal biopsy. Their treatments were decided by an individual nephrologist and not affected by the study. Disease progression was measured by the rate of GFR decline [18], which was calculated by the least-squares regression method.

\section{Statistical Analysis}

Statistical analysis was performed by SPSS for Windows version 11.0 (SPSS, Inc., Chicago, Ill., USA). All results were presented as mean \pm SD for normally distributed data and median (lower and upper quartiles) for the others. Since data of gene expression levels were highly skewed, nonparametric statistical methods were used. We used the Mann-Whitney $U$ test to compare gene expression levels between groups and Spearman's rank-order correlations to test associations between gene expression levels and clinical parameters. $\mathrm{p}<0.05$ was considered statistically significant. All probabilities were two-tailed.

\section{Results}

The demographic and baseline clinical data of the study subjects are summarized in table 1 . Compared with kidney donors, hypertensive subjects were older, had a significantly higher blood pressure, more severe renal tissue damage and worse renal function. Amongst the HTN group, 23 patients $(56.1 \%)$ were treated with ACE inhibitor, $2(4.9 \%)$ with ARB, 19 (46.3\%) with $\beta$-blocker, and 19 (46.3\%) with calcium channel blocker.
Table 1. Demographic and baseline clinical data

\begin{tabular}{lcc}
\hline Parameters & Patients & Kidney donors \\
\hline Male:female & $31: 10$ & $4: 6$ \\
Age, years & $57.04 \pm 13.07$ & $36.36 \pm 13.73$ \\
Systolic BP, mm Hg & $143.66 \pm 13.83$ & $114.36 \pm 14.20$ \\
Diastolic BP, mm Hg & $81.83 \pm 7.75$ & $69.45 \pm 9.77$ \\
Proteinuria, g/day & $1.84 \pm 2.91$ & - \\
Serum creatinine, $\mu$ mol/1 & $238.56 \pm 234.36$ & $82.73 \pm 13.98$ \\
eGFR, ml/min/1.73 m ${ }^{2}$ & $41.88 \pm 25.10$ & $106.64 \pm 22.03$ \\
Glomerulosclerosis, \% & $32.27 \pm 24.98$ & $2.63 \pm 5.27$ \\
Tubulointerstitial fibrosis, \% & $33.66 \pm 24.20$ & $1.36 \pm 2.34$ \\
\hline
\end{tabular}

\section{Comparison of ACE and ACE2 Levels between \\ Patients and Kidney Donors}

The intrarenal mRNA expression levels of ACE and ACE2 in patients with HTN and kidney donors are summarized in figure 1. In brief, the glomerular mRNA expression levels of ACE were similar between HTN and CTL [ACE: $0.92(0.00,3.56)$ vs. $0.84(0.00,3.26), \mathrm{p}=$ 0.923], while the glomerular ACE2 expression of HTN was marginally higher than that of CTL, although the difference fell short of statistical significance [3.58 (0.00, $14.74)$ vs. $1.16(0.00,1.87), \mathrm{p}=0.091]$. The tubulointerstitial expression of ACE was marginally higher in HTN than CTL $[2.28(1.30,4.45)$ vs. $1.21(0.41,1.91), \mathrm{p}=0.096]$. In contrast, the tubulointerstitial expression of ACE2 was significantly higher in HTN than CTL [3.09 (1.46, $4.85)$ vs. $1.09(0.44,1.98), p=0.042]$. Subgroup analysis showed that the glomerular mRNA expression of ACE2 was marginally lower for patients who were receiving ACE inhibitor than for those who were not [2.33 (0.00, $3.48)$ vs. $7.94(0.97,23.73), p=0.069]$, while the glomeru- 
Fig. 2. Immunohistochemistry of renal tissue: a ACE in HTN group, b ACE in CTL group, c ACE2 in HTN group, and d ACE2 in CTL group. Micrographs were taken at $400 \mathrm{~s}$.
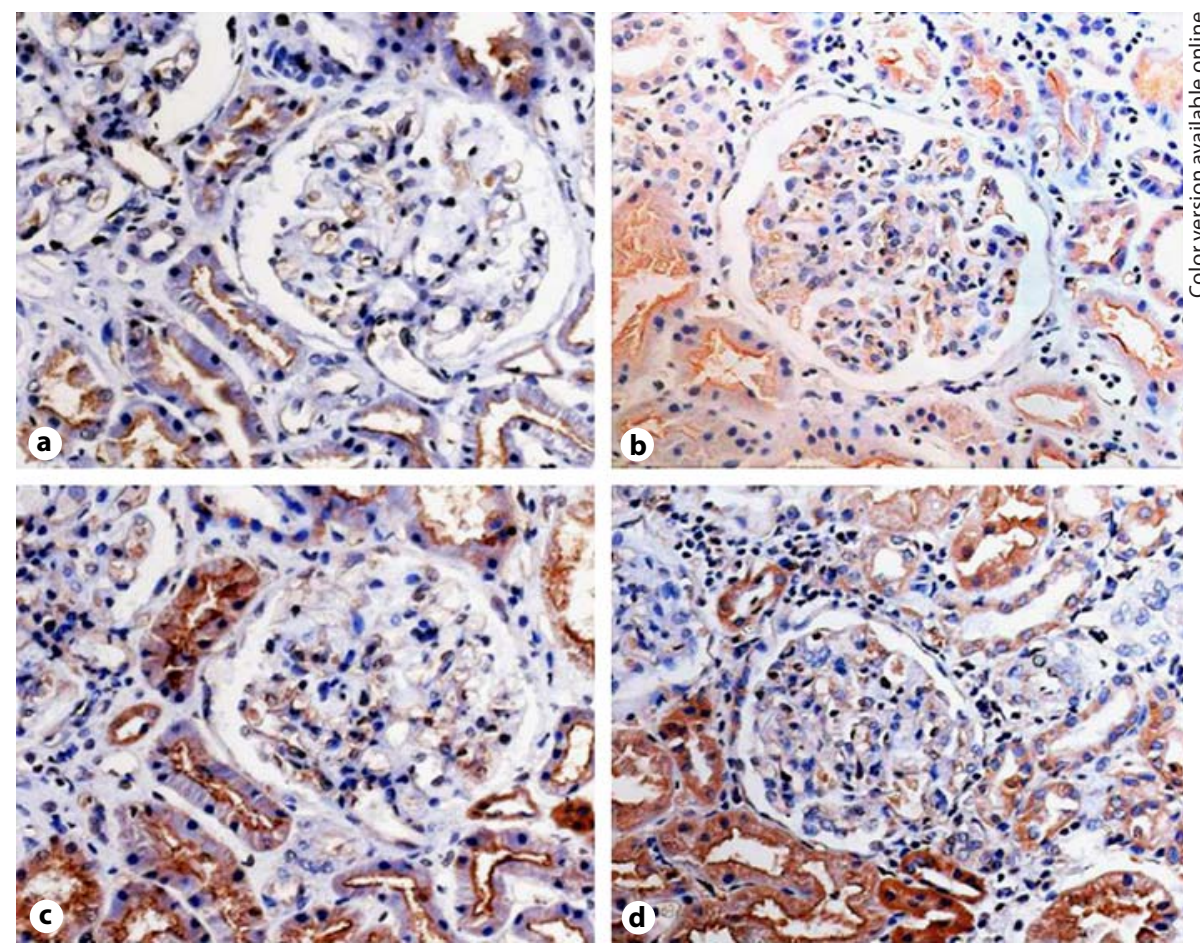

Fig. 3. Comparisons of intrarenal ACE and ACE2 at protein level between patients with HTN ( $\square$ ) and normal CTL (橉): a glomerular and b tubulointerstitial expression. Data are compared by the MannWhitney U test.

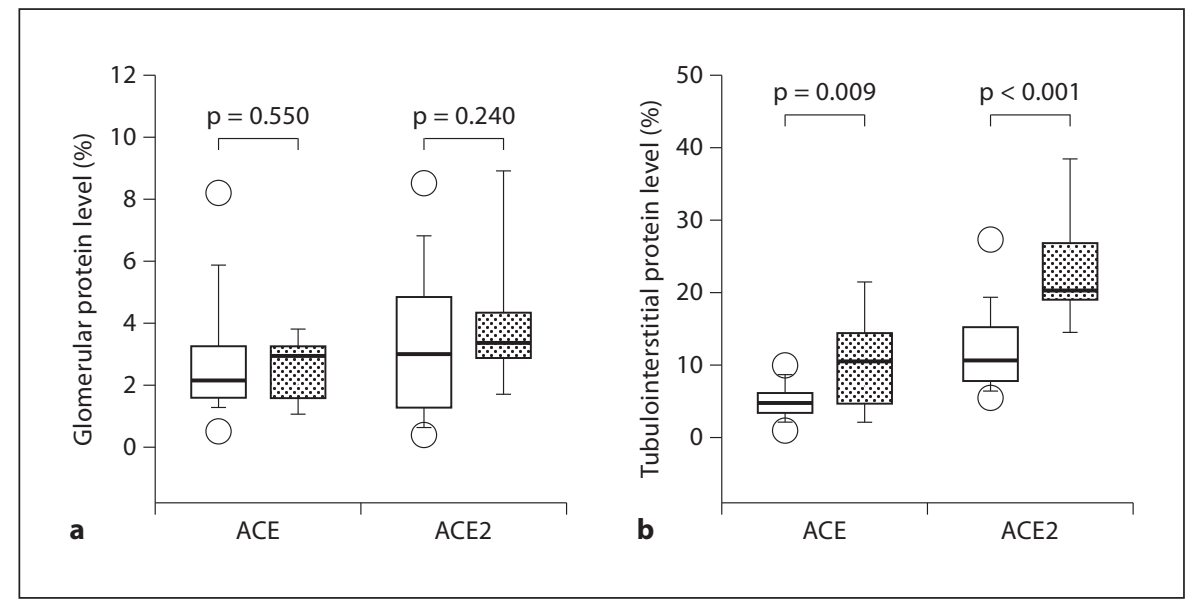

lar ACE expression and tubulointerstitial mRNA expression of ACE and ACE2 were similar between patients who were and were not receiving ACE inhibitor (details not shown).

The protein levels of ACE and ACE2 in HTN and CTL are quantified by immunohistochemistry (fig. 2) and summarized in figure 3. In brief, the glomerular ACE and ACE2 levels were similar between HTN and CTL (details not shown). In contrast, both the tubulointerstitial ACE and ACE2 levels were significantly lower in HTN than
CTL [ACE: $5.31(3.64,7.27)$ vs. $10.50(4.59,14.43), \mathrm{p}=$ 0.009; ACE2: $11.54(7.85,17.17)$ vs. $20.28(18.88,26.98)$, $\mathrm{p}=0.001]$. Both the glomerular and tubulointerstitial levels of ACE and ACE2 were similar between patients who were and were not receiving ACE inhibitor (details not shown).

Correlations with Baseline Clinical Parameters

There is no correlation between the ACE and ACE2 levels in glomerulus or tubulointerstitium and protein- 
Fig. 4. Correlations between estimated GFR and tubulointerstitial $\mathbf{a}$ ACE and $\mathbf{b}$ ACE2 protein level. Data are analyzed by Spearman's rank correlation.
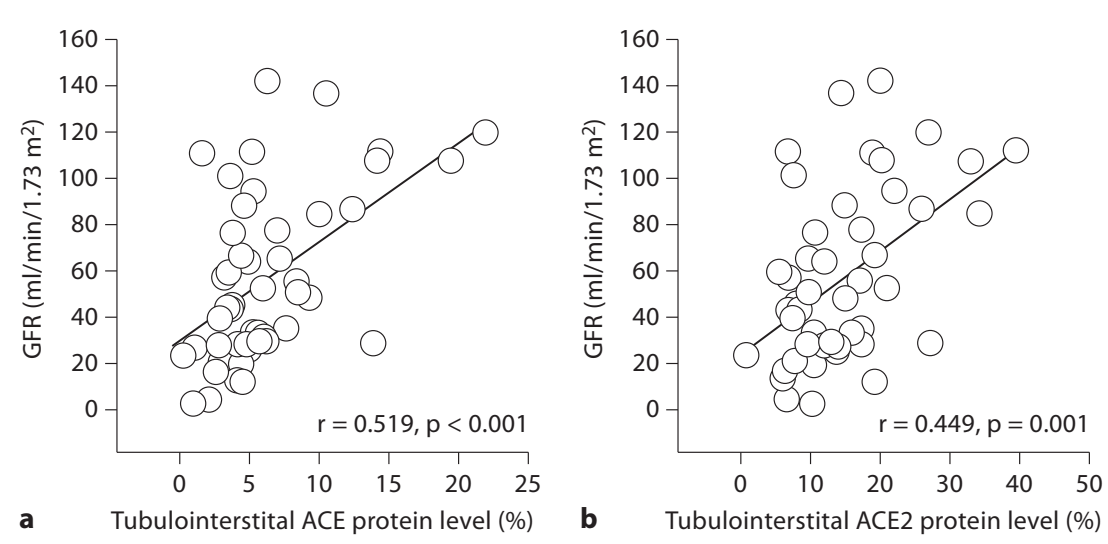

Fig. 5. Correlations between the degree of glomerulosclerosis and a glomerular ACE and $\mathbf{b}$ glomerular ACE2 levels, and correlations between the degree of tubulointerstitial scarring and c tubulointerstitial ACE and $\mathbf{d}$ ACE2 protein level. Data are analyzed by Spearman's rank correlation.
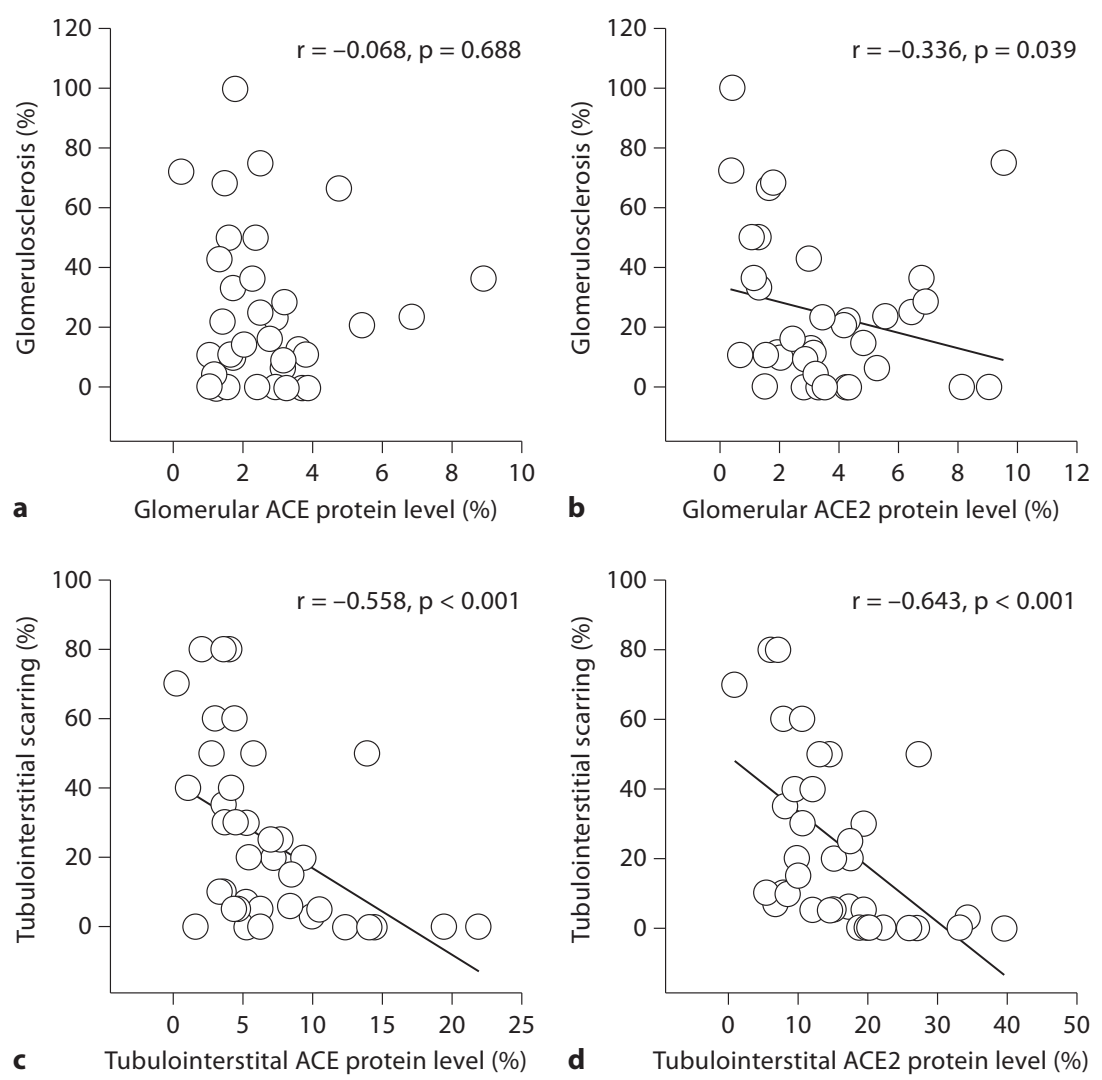

uria or blood pressure in the HTN group (details not shown). However, both the tubulointerstitial ACE ( $\mathrm{r}=$ $0.519, \mathrm{p}<0.001)$ and ACE2 protein levels $(\mathrm{r}=0.449, \mathrm{p}<$ $0.001)$ significantly correlated with estimated GFR (fig. 4).

\section{Correlations with Histological Damage}

The degree of glomerulosclerosis had a modest but statistically significant correlation with the glomerular ACE2 level $(r=-0.336, p=0.039)$, but not with the glomerular ACE level $(r=-0.068, p=0.688)$ (fig. 5). The de- 
Fig. 6. Correlations between the rate of GFR decline and glomerular a ACE and b ACE2 protein level. For the rate of GFR decline ( $\mathrm{ml} / \mathrm{min} /$ year), a negative value indicates worsening of renal function. Data are analyzed by Spearman's rank correlation.
Fig. 7. Correlations between the ratio of glomerular level of ACE to ACE2 and $\mathbf{a}$ the degree of glomerulosclerosis and $\mathbf{b}$ estimated GFR. Data are analyzed by Spearman's rank correlation.
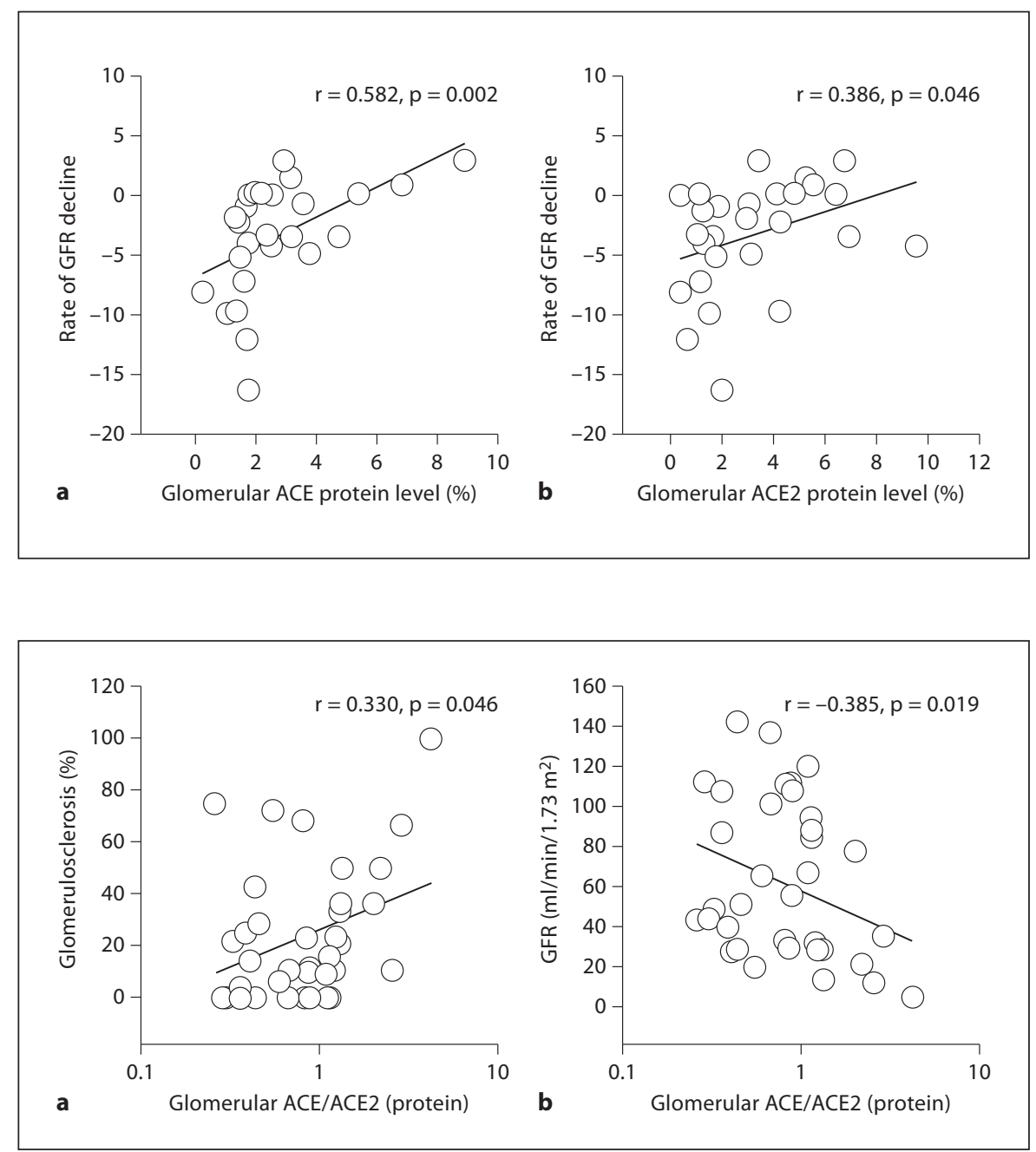

gree of tubulointerstitial scarring, in contrast, significantly correlated with the tubulointerstitial ACE $(\mathrm{r}=-0.558$, $\mathrm{p}<0.001)$ and ACE2 levels $(\mathrm{r}=-0.643, \mathrm{p}<0.001)$ (fig. 5).

\section{Correlations with Renal Function Decline Rate}

The average duration of follow-up was $27.19 \pm 9.29$ months; the average rate of GFR decline was $-4.06 \pm 5.48$ $\mathrm{ml} / \mathrm{min} /$ year. The rate of GFR decline significantly correlated with the glomerular ACE $(\mathrm{r}=0.582, \mathrm{p}=0.002)$ and ACE2 levels $(r=0.386, p=0.046)$ (fig. 6), but not with the tubulointerstitial ACE $(r=0.186, p=0.257)$ or ACE2 levels $(r=0.227, p=0.165)$.

\section{ACE/ACE2 Ratio}

The ratio of glomerular ACE/ACE2 level correlated with the degree of glomerulosclerosis $(r=0.330, p=$ $0.046)$ and inversely with the estimated GFR $(r=-0.385$, $\mathrm{p}=0.019)$ (fig. 7). On the other hand, the tubulointerstitial ACE/ACE2 ratio did not correlate with any clinical or histological parameter (details not shown).

\section{Discussion}

In the present study, we found a predominant presence of ACE and ACE2 in the tubulointerstitium. The tissue ACE and ACE2 levels were significantly decreased in patients with HTN; the magnitude of reduction correlated with the degree of renal failure and tubulointerstitial scarring. Notably, there was discordance between the protein level and mRNA expression of ACE or ACE2. We also found that the glomerular ACE and ACE2 level significantly correlated with the rate of renal function decline. 
The intrarenal expression of ACE and ACE2 under pathological conditions has been extensively investigated in animal models, and the results were variable. ACE mRNA expression was reported to be unchanged [19] or decreased [20,21], and protein expression was reported to be decreased [21] in diabetic models. ACE2 mRNA expression was also reported to be unchanged $[21,22]$ or decreased [20], and protein expression was reported to be increased [22] in diabetic models, or decreased [23] in hypertensive models. Data on the intrarenal expression of ACE and ACE2 in humans is limited. In patients with diabetic nephropathy, ACE mRNA and protein expression was reported to be increased [24, 25]; ACE2 mRNA expression was reported to be unchanged and protein expression was reported to be decreased $[24,25]$. This heterogeneity of study results is not well explained. It is, however, important to note that these studies investigated different species and animal models, and the duration or severity of nephropathy were highly variable. All these factors might cause this discordance in study results $[25$, 26]. Furthermore, different parts of renal tissue (i.e. glomeruli and tubulointerstitium) might be studied, whose expression of ACE and ACE2 might not be modulated synchronously $[20,25]$. In the present study, we found that intrarenal expression of ACE and ACE2 was mainly in the tubulointerstitial area, which was consistent with previous studies $[25,27]$. These results suggest that tubulointerstitial RAS might play an important role in the pathophysiology of HTN, which is similar to the observation in diabetic nephropathy [28]. On the other hand, we observed that the glomerular, but not the tubulointerstitial, ACE and ACE2 levels correlated with the rate of renal function decline, indicating that intraglomerular RAS may be relevant for the progression of HTN.

A previous study by Wakahara et al. [29] showed that the intrarenal expression is parallel in both ACE and ACE2. In line with this, we also found significant internal correlations between the glomerular as well as tubulointerstitial ACE and ACE2 at mRNA and protein levels (details not shown), and the ACE and ACE2 levels simultaneously correlated with clinical and histological parameters in the present study. At first glance, it seems paradoxical since ACE and ACE2 act antagonistically on the formation of angiotensin II. However, we further found that the ratio of glomerular ACE and ACE2 level correlated with the degree of glomerulosclerosis and inversely correlated with the estimated GFR. Although we did not measure the actual tissue level of angiotensin II, it is possible that a higher ACE/ACE2 ratio would result in an excess production of angiotensin II and aggravate renal injury. Taken together, these results suggest that it is the balance between ACE and ACE2 that governs the severity of renal injury in HTN.

Our results reconfirmed previous observations that the intrarenal expression of ACE and ACE2 might be modulated at the posttranscriptional level since mRNA and protein expression of ACE and ACE2 were not congruently regulated $[21,22]$. In fact, we did not find any correlation between the mRNA expression and protein level of ACE or ACE2 in the present study, and it was the protein level rather than the mRNA expression of ACE or ACE2 that correlated with clinical or histological parameters (details not shown). Our results highlight the fact that data based on the intrarenal mRNA expression of ACE and ACE2 should be interpreted with caution.

We did not find any significant difference in the intrarenal ACE or ACE2, both in terms of mRNA expression or protein level, between patients who were taking ACE inhibitor or not. This observation may seem unexpected. However, it is well reported that the apparent drug tolerance in patients receiving chronic ACE inhibitor therapy is a result of the production of angiotensin II by alternative enzymes (e.g. chymase) rather than an alteration in the activity of ACE [30]. Since the number of patients who were taking ARB was small, subgroup analysis was not performed, and they were excluded from the analysis for the effect of ACE inhibitor.

There are several weaknesses of our study. First, since HTN is normally diagnosed clinically and renal biopsy is not a routine investigation in patients with essential hypertension, selection bias might exist in our study population, which possibly only included patients with atypical clinical characteristics and might be different from patients with ordinary essential hypertension that are commonly seen in daily clinical practice. Second, many of our patients were treated with some form of RASblocking therapy, which may influence the intrarenal expression of ACE or ACE2 [20,31]. Thus, the results in the present study might reflect physiological response to treatment but not truly reflect changes in HTN. In theory, it would be interesting to measure the ACE and ACE2 activity in urine, which should reflect a renal source of the enzyme. Unfortunately, because of the limitation in the original design of our study, urine enzyme activity was not measured. Since other enzymes could contribute to angiotensin II and angiotensin 1-7 formation (e.g. chymase and neutral endopeptidase), it would also be interesting to explore their expression and relation with hypertensive renal damage in further studies. Finally, renal 
tissue from transplant donors was used as CTL in this study. However, there could be tissue injury in donor kidneys because of hemodynamic fluctuation and perfusing solution, and the intrarenal expression of ACE or ACE2 might change accordingly. In the present study, we did not test the specificity of the immunostaining because antibodies for both ACE and ACE2 were obtained from a commercial source, with specificity verified by the manufacturer by Western blotting and blocking experiments $[32,33]$, and they had been used with satisfactory results in previous studies $[34,35]$.

In summary, we found that the tubulointerstitial protein levels of ACE and ACE2 are decreased in patients with HTN, and the magnitude of reduction was related to the degree of renal failure and histological damage. On the other hand, the glomerular protein level of ACE and ACE2 correlated with the rate of renal function decline.
We also found that there was discordance between the protein level and mRNA expression of renal ACE or ACE2. The results suggest that the balance between intrarenal ACE and ACE2 may play an important role in the pathogenesis and progression of HTN.

\section{Acknowledgements}

This study was supported in part by the Hong Kong Society of Nephrology Research Grant, CUHK research accounts 6901031 and 7101215, and the National Natural Science Foundation of China (project 81000287).

\section{Disclosure Statement}

The authors have no conflicts of interest to declare.

\section{References}

1 USRDS: 2007 Annual Data Report: Atlas of End-Stage Renal Disease in the United States. Bethesda, National Institutes of Health, National Institute of Diabetes and Digestive and Kidney Diseases, 2007.

2 ERA-EDTA: Registry 2005 Annual Report. Amsterdam, Academic Medical Centre, 2007.

$\checkmark 3$ Opie LH: Renoprotection by angiotensin-receptor blockers and ACE inhibitors in hypertension. Lancet 2001;358:1829-1831.

$\checkmark 4$ Navar LG: The intrarenal renin-angiotensin system in hypertension. Kidney Int 2004;65: 1522-1532.

5 Kobori H, Nangaku M, Navar LG, Nishiyama A: The intrarenal renin-angiotensin system: from physiology to the pathobiology of hypertension and kidney disease. Pharmacol Rev 2007;59:251-287.

-6 Bidani AK, Griffin KA: Pathophysiology of hypertensive renal damage: implications for therapy. Hypertension 2004;44:595-601.

7 Fakhouri F, Placier S, Ardaillou R, Dussaule JC, Chatziantoniou C: Angiotensin II activates collagen type I gene in the renal cortex and aorta of transgenic mice through interaction with endothelin and TGF- $\beta$. J Am Soc Nephrol 2001;12:2701-2710.

$>8$ Dussaule JC, Tharaux PL, Boffa JJ, Fakhouri F, Ardaillou R, Chatziantoniou C: Mechanisms mediating the renal profibrotic actions of vasoactive peptides in transgenic mice. J Am Soc Nephrol 2000;11(suppl 16):S124-S128

-9 Lai KN, Leung JC, Lai KB, To WY, Yeung VT, Lai FM: Gene expression of the renin-angiotensin system in human kidney. J Hypertens 1998;16:91-102.
10 Burrell LM, Johnston CI, Tikellis C, Cooper ME: ACE2, a new regulator of the renin-angiotensin system. Trends Endocrinol Metab 2004;15:166-169.

11 Thomas MC, Tikellis C: ACE2: an ACE up the sleeve? Curr Enzym Inhib 2005;1:51-63.

12 Fogo A, Weedman B, Solez K: Hypertensive nephrosclerosis; in Atlas of Renal Pathology. Nashville, The National Kidney Foundation, 1999.

13 Levey AS, Bosch JP, Lewis JB, Greene T, Rogers N, Roth D: A more accurate method to estimate glomerular filtration rate from serum creatinine: a new prediction equation. Modification of Diet in Renal Disease Study Group. Ann Intern Med 1999;130:461-470.

14 Chan RW, Lai FM, Li EK, Tam LS, Chow KM, Lai KB, Li PK, Szeto CC: Intrarenal cytokine gene expression in lupus nephritis. Ann Rheum Dis 2007;66:886-892.

15 Applied Biosystems: Guide to Performing Relative Quantitation of Gene Expression Using Real-Time Quantitative PCR. Foster City, Applied Biosystems, 2004.

16 Wang G, Lai FM, Lai KB, Chow KM, Li KT, Szeto CC: Messenger RNA expression of podocyte-associated molecules in the urinary sediment of patients with diabetic nephropathy. Nephron Clin Pract 2007;106: c169-c179.

17 Szeto CC, Chow KM, Lai KB, Szeto CY, Chan RW, Kwan BC, Chung KY, Li PK, Lai FM: mRNA expression of target genes in the urinary sediment as a noninvasive prognostic indicator of CKD. Am J Kidney Dis 2006;47: 578-586.
18 Mitch W: Measuring the rate of progression of renal insufficiency; in Mitch WE, Stein J, Brenner BM (eds): The Progressive Nature of Renal Disease. New York, Churchill Livingstone, 1986, pp 203-220.

19 Ichihara A, Hayashi M, Kaneshiro Y, Suzuki F, Nakagawa T, Tada Y, Koura Y, Nishiyama A, Okada H, Uddin MN, et al: Inhibition of diabetic nephropathy by a decoy peptide corresponding to the 'handle' region for nonproteolytic activation of prorenin. J Clin Invest 2004;114:1128-1135.

20 Tikellis C, Johnston CI, Forbes JM, Burns WC, Burrell LM, Risvanis J, Cooper ME: Characterization of renal angiotensin-converting enzyme 2 in diabetic nephropathy. Hypertension 2003;41:392-397.

21 Wysocki J, Ye M, Soler MJ, Gurley SB, Xiao HD, Bernstein KE, Coffman TM, Chen S, Batlle D: ACE and ACE2 activity in diabetic mice. Diabetes 2006;55:2132-2139.

-22 Ye M, Wysocki J, Naaz P, Salabat MR, LaPointe MS, Batlle D: Increased ACE2 and decreased ACE protein in renal tubules from diabetic mice: a renoprotective combination? Hypertension 2004;43:1120-1125.

23 Zhong JC, Huang DY, Yang YM, Li YF, Liu GF, Song XH, Du K: Upregulation of angiotensin-converting enzyme 2 by all-trans retinoic acid in spontaneously hypertensive rats. Hypertension 2004;44:907-912.

24 Konoshita T, Wakahara S, Mizuno S, Motomura M, Aoyama C, Makino Y, Kawai Y, Kato N, Koni I, Miyamori I, et al: Tissue gene expression of renin-angiotensin system in human type 2 diabetic nephropathy. Diabetes Care 2006;29:848-852. 
-25 Mizuiri S, Hemmi H, Arita M, Ohashi Y, Tanaka Y, Miyagi M, Sakai K, Ishikawa Y, Shibuya K, Hase H, et al: Expression of ACE and ACE2 in individuals with diabetic kidney disease and healthy controls. Am J Kidney Dis 2008;51:613-623.

-26 Ingelfinger JR: ACE2: a new target for prevention of diabetic nephropathy? J Am Soc Nephrol 2006;17:2957-2959.

-27 Lely AT, Hamming I, van Goor H, Navis GJ: Renal ACE2 expression in human kidney disease. J Pathol 2004;204:587-593.

-28 Mezzano S, Droguett A, Burgos ME, Ardiles LG, Flores CA, Aros CA, Caorsi I, Vio CP, Ruiz-Ortega M, Egido J: Renin-angiotensin system activation and interstitial inflammation in human diabetic nephropathy. Kidney Int 2003;64(suppl 86):S64-S70.
29 Wakahara S, Konoshita T, Mizuno S, Motomura M, Aoyama C, Makino Y, Kato N, Koni I, Miyamori I: Synergistic expression of angiotensin-converting enzyme (ACE) and ACE2 in human renal tissue and confounding effects of hypertension on the ACE to ACE2 ratio. Endocrinology 2007; 148:24532457.

-30 Bomback AS, Klemmer PJ: The incidence and implications of aldosterone breakthrough. Nat Clin Pract Nephrol 2007;3: 486-492.

-31 Jessup JA, Gallagher PE, Averill DB, Brosnihan KB, Tallant EA, Chappell MC, Ferrario CM: Effect of angiotensin II blockade on a new congenic model of hypertension derived from transgenic Ren-2 rats. Am J Physiol Heart Circ Physiol 2006;291:H2166-H2172.

32 Santa Cruz Biotechnology, Inc. ACE (H-170): sc-20791. Website: http://datasheets.scbt. com/sc-20791.pdf (last accessed on January 10, 2011).
33 Abcam: Angiotensin-converting enzyme 2 antibody (ab15348). Website: http://www. abcam.com/Angiotensin-ConvertingEnzyme-2-antibody-ab15348.html (last accessed on January 10, 2011).

34 Hemming ML, Selkoe DJ: Amyloid $\beta$-protein is degraded by cellular angiotensin-converting enzyme (ACE) and elevated by an ACE inhibitor. J Biol Chem 2005;280:3764437650.

35 Wang G, Lai FM, Lai KB, Chow KM, Kwan $\mathrm{CH}, \mathrm{Li} \mathrm{KT}$, Szeto CC: Discrepancy between intrarenal messenger RNA and protein expression of ACE and ACE2 in human diabetic nephropathy. Am J Nephrol 2009;29: 524-531. 